\title{
Comparative hydrolysis analysis of cellulose samples and aspects of its application in conservation science
}

\author{
Manuel Becker $\cdot$ Kyujin Ahn • Markus Bacher $\cdot$ Chunlin Xu • Anna Sundberg • \\ Stefan Willör $\cdot$ Thomas Rosenau $\cdot$ Antje Potthast 1
}

Received: 18 April 2021/Accepted: 26 June 2021 / Published online: 23 July 2021

(C) The Author(s) 2021

\begin{abstract}
Knowledge about the carbohydrate composition of pulp and paper samples is essential for their characterization, further processing, and understanding the properties. In this study, we compare sulfuric acid hydrolysis and acidic methanolysis, followed by GC-MS analysis of the corresponding products, by means of 42 cellulose and polysaccharide samples. Results are discussed and compared to solid-state NMR (crystallinity) and gel permeation chromatography (weight-averaged molecular mass) data. The use of the hydrolysis methods in the context of cellulose conservation science is evaluated, using e-beam treated and artificially aged cellulose samples.
\end{abstract}

Supplementary Information The online version contains supplementary material available at https://doi.org/10.1007/ s10570-021-04048-6.

M. Becker · K. Ahn · M. Bacher .

T. Rosenau · A. Potthast $(\bowtie)$

Department of Chemistry, Institute of Chemistry of

Renewables, University of Natural Resources and Life

Sciences, Muthgasse 18, Vienna 1190, Austria

e-mail: antje.potthast@boku.ac.at

K. Ahn

National Archives of Korea, 30 Daewangpangyo-ro

851 beon-gil, Sujeong-gu, Seongnam-si, Korea

C. Xu · A. Sundberg · S. Willför · T. Rosenau c/o Laboratory of Natural Materials Technology, Johan Gadolin Process Chemistry Centre, Åbo Akademi

University, Porthaninkatu 3, 20500 Turku, Finland
Keywords Cellulose $\cdot$ Crystallinity $\cdot$ Electron beam irradiation · Hemicellulose $\cdot$ Methanolysis $\cdot$ Sulfuric acid hydrolysis $\cdot$ Historic paper

\section{Introduction}

The carbohydrate composition of pulp and paper samples is a key parameter for the characterization of their chemical and physical properties and for their further processing (Willför et al. 2005a, b, 2009; Sundberg et al. 2003). While chemically pure cellulose is theoretically only composed of (anhydro)glucose units, real-world cellulosic samples are far from being that ideal: pulps contain hemicelluloses, papers contains sizing agents and fillers, e.g. starch, and historic paper samples may contain stabilizers and additives. Gum Arabic or pectins are two well-known and analytically well characterized examples, but often those additives are of unknown structure and origin. Obtaining knowledge about the carbohydrate composition is obviously a first and important step in the material characterization. In most cases, carbohydrate composition is determined by hydrolysis and quantification of the obtained monomers by chromatographic methods (Black and Fox 1996). Alternative spectroscopic methods on the intact polymer, such as IR or NMR, are insufficient when it comes to quantification of the contained monosaccharides, 
especially of minor components. Hydrolysis, in this regard, is synonymous with cleavage of the glycosidic bonds of the polysaccharides. Both enzymatic and acidic hydrolysis, when performed exhaustively, release the monosaccharides as the final subunits of a polysaccharide. Acid hydrolysis can involve sulfuric acid, trifluoroacetic acid, or hydrochloric acid under strong conditions, mostly in aqueous medium, or milder environments, e.g. in organic solvents with catalytic amounts of acid (Bertaud et al. 2002). The liberated monosaccharides are usually subsequently analyzed by HPLC (Bose et al. 2009; Galant et al. 2015), GC (Sundberg et al. 1996) or NMR (Marques et al. 2010; Duquesnoy et al. 2008).

There are obvious differences in the rates of acidic hydrolysis of poly- and oligosaccharides which originate in reactivity differences of the glycosidic linkages. The type of monosaccharide (e.g. glucose vs. mannose vs. xylose), anomer $(\alpha / \beta)$, linkage (e.g. $\beta$ - $O$ 3 vs. $\beta-O-4$, vs. $\beta-O-6$ ), neighboring activating or deactivating groups (such as ether, keto or carboxylic acid moieties) and their position, and the surrounding hydrogen bond system are major influencing factors (Yoneda et al. 2016). Hydrolysis efficiency is of course also affected by the conditions, such as the type, strength and concentration of acid used, duration of the hydrolysis treatment, and reaction temperature (Panagiotopouos 2005). Two general hydrolysis approaches, with several sub-variants, have become the generally accepted and frequently used standard approaches for compositional carbohydrate analysis: total hydrolysis with sulfuric acid and acidic methanolysis. Each of it has its own advantages and disadvantages which have to be weighed against each other for a particular application or sample set.

Hydrolysis with sulfuric acid converts polysaccharides into monosaccharides. The advantage of the method is the high conversion, reflected in mostly complete solubilization of the starting material and the common term "total hydrolysis". Also substrates that are "hydrolysis-resistant" because of physical traits (high crystallinity) or attenuating chemical influences (polyuronic acids) are reliably converted. However, the strong acidity and the harsh conditions entail lots of side reactions as a major drawback. Uronic acids decarboxylate, sulfuric acid groups might be introduced, and monosaccharides once formed, in particular keto sugards, are converted into their primary furanoid condensation/dehydratization products, such as furfural or 5-hydroxymethylfurfural, and follow-up compounds.

Relative to sulfuric acid-based total hydrolysis, acidic methanolysis represents a comparatively mild hydrolysis method, which largely avoids such side reactions, albeit at the expense of incomplete conversion of hard-to-hydrolyze material (Chambers and Clamp 1971). The liberated monosaccharides are converted into their corresponding methyl glycosides, and carboxyl units of uronic acids are converted into their methyl esters (Huang et al. 1992). The methyl glycosides formed lose their anomeric information and equilibrate to $\alpha$ - and $\beta$-furanoses and pyranoses (Laine et al. 2002). The fact of increased analytical complexity - a single monosaccharide can appear in the form of up to four cyclic isomers after acidic methanolysis-was often portrayed as severe drawback, but is now viewed in a more differentiated way. Evidently, the formation of more isomers per monosaccharide leads to an increase in chromatogram complexity and may decrease the sensitivity of analysis because signal intensity of one analyte is distributed over several peaks (Rumpel and Dignac 2006). However, this signal splitting reduces the frequent risk of complete peak overlapping, and the constant ratio of isomers for a given monosaccharide enables compound identification and quantification on one of the up to four peaks (Laine et al. 2002; Amelung et al. 1996). The advantage of acidic methanolysis, compared to sulfuric acid hydrolysis, is much less unwanted degradation and byproduct formation, in particular of fragile hemicelluloses, and the possibility to assess and quantify uronic acids (Chambers and Clamp 1971). This is offset by the fact that crystalline cellulose domains are affected only slightly, so that for such material the strong acid hydrolysis methods is recommended (Sundberg et al. 1996). Unfortunately, a hydrolysis method that combines the best of both worlds - complete hydrolysis of the resistant lignocellulose and no side reactions of the labile hemicellulose degradation products-does not yet exist. Thus, total glucose, pentoses, and uronic acids are not accessible by a single hydrolysis method, so both approaches must still be combined to get maximum information.

The carbohydrate composition of papers and similar cellulosic materials shows a predominance of glucose, evidently from cellulose being the major constituent, and smaller amounts of pentoses, hexoses, 
or deoxy sugars and sugar acids. These originate from the hemicellulose fraction (glucuronoxylan, galactoglucomannan) or from carbohydrate-based stabilizers or additives (Gum Arabic, guar gum, pectins).

In this study, the mentioned two hydrolysis methods, sulfuric acid hydrolysis and acidic methanolysis, were applied to characterize monomer composition of cellulose samples and related polysaccharides, covering a wide range of monosaccharides and sugar acid compounds. The determination of the whole cellulose/total glucose content was carried out by sulfuric acid hydrolysis according to Bose et al. (2009) The analysis of the hemicellulose fractions, pectins and additives adopted the method of Sundberg et al. (1996), using acidic methanolysis followed by derivatization/gas chromatography (GC). Attempts were made to determine whether the methods would be useful in characterizing the effects of electron beam irradiation (e-beam) or cellulose conservation treatments such as artificial aging, and whether they would indicate changes in monomer composition upon such treatments. Electron beam radiation can be used to treat mold infested collections to deactivate microorganisms. The hydrolysis data from the two alternative methods were compared and correlated with data from solid-state NMR spectroscopy (crystallinity) and gel permeation chromatography analysis (weight-average molar mass, $\mathrm{M}_{\mathrm{w}}$ ).

\section{Material and methods}

Chemicals and reagents

The reference compounds D-(-)-arabinose, D- $(+)-$ galactose, D-(+)-glucose, D- $(+)$-mannose, L- $(+)$ rhamnose (6-deoxy-mannose), D-(+)-xylose, D- $(+)-$ galacturonic acid monohydrate (GalA), D-glucuronic acid (GlcA), the internal standard sorbitol, anhydrous pyridine, acetic acid, ethyl acetate, sodium carbonate $\left(\mathrm{Na}_{2} \mathrm{CO}_{3}\right), \quad \mathrm{N}, \mathrm{O}$-bis(trimethylsilyl)trifluoroacetamide (BSTFA), trimethylchlorosilane (TMCS) and 4-(dimethylamino)pyridine (DMAP) were purchased from Sigma-Aldrich/Fluka (Sigma-Aldrich Schnelldorf, Germany). All standards, chemicals, and reagents were of p.a. grade and used without further purification.
Materials

All polysaccharide (Table 1), cellulose pulp (Table 2) and paper (Table 3) samples were freeze-dried prior analysis. For acidic methanolysis, amounts of 1-2 mg in the case of polysaccharides and $10 \mathrm{mg}( \pm 2 \mathrm{mg})$ in the cellulose pulps or papers were used for analysis. The sulfuric acid hydrolysis was conducted with sample amounts of $40 \mathrm{mg}( \pm 1 \mathrm{mg})$ for all substrates.

Sulfuric acid hydrolysis

Sulfuric acid hydrolysis of polysaccharides was conducted according to a procedure by Bose et al. (2009), which was modified employing a two-step treatment at different acid concentrations followed by derivatization-GC-MS analysis. In the primary hydrolysis step, $1.5 \mathrm{~mL}$ of $72 \%$ aqueous $\mathrm{H}_{2} \mathrm{SO}_{4}$ was added to the sample $(40 \pm 1 \mathrm{mg})$ in a vial, followed by stirring at room temperature for $2 \mathrm{~h}$. For the second hydrolysis step, $2 \mathrm{~mL}$ of $\mathrm{H}_{2} \mathrm{O}$ was added and the mixture was heated in an oven at $80{ }^{\circ} \mathrm{C}$ for $1 \mathrm{~h}$. The hydrolysis solution was cooled down in an ice bath and stored at $4{ }^{\circ} \mathrm{C}$ overnight. Internal standard solution $(150 \mathrm{mg}$ of sorbitol in $100 \mathrm{~mL}$ of $\mathrm{H}_{2} \mathrm{O}, 7 \mathrm{~mL}$ ) were added to the hydrolysis solution. An aliquot of $1.5 \mathrm{~mL}$ was neutralized with solid $\mathrm{Na}_{2} \mathrm{CO}_{3}$ (approx. $290 \mathrm{mg}$ ) until bubble generation due to $\mathrm{CO}_{2}$ evolution subsided. The solution was filtered $(0.45 \mu \mathrm{m}, 13 \mathrm{~mm}$ diameter $)$ into a new GC vial and the $\mathrm{pH}$ value was adjusted to 7 by adding 1-2 drops of acetic acid (control with indicator paper).

\section{Acidic methanolysis}

The protocol was based on the procedure by Sundberg et al. (1996). ${ }^{18}$ In a vial, the dried sample materials (1-2 mg of polysaccharides or $10 \pm 2 \mathrm{mg}$ of cellulosic pulps/papers) were added into a solution of $\mathrm{HCl}$ in anhydrous methanol ( $2 \mathrm{M}, 2 \mathrm{~mL})$. A calibration solution $(1 \mathrm{~mL})$ containing $0.1 \mathrm{mg} / \mathrm{mL}$ of sugar monomers and uronic acids was subjected to acidic methanolysis in a separate vial but under the same conditions. The vials were sealed and the samples kept at $100{ }^{\circ} \mathrm{C}$ for $3 \mathrm{~h}$. After cooling to room temperature, samples were neutralized by adding pyridine $(100 \mu \mathrm{L})$. Internal standard solution $(0.1 \mathrm{mg}$ of 
Table 1 Sample list of polysaccharides analyzed

\begin{tabular}{lllll}
\hline & Polysaccharides & Code & Origin & Producer \\
\hline P1 & Arabinan & AS & Sugar Beet & Megazyme \\
P2 & Arabinan-Debranched & DA & Sugar Beet & Megazyme \\
P3 & Arabinan-Linear 1,5- $\alpha$-L & L $<$ A & Sugar Beet & Megazyme \\
P4 & Galactan & GG & Potato & Megazyme \\
P5 & Pectic galactan & GL & Lupin & Megazyme \\
P6 & Pectic galactan & GP & Potato & Megazyme \\
P7 & Galactomannan & GC & Carob & Megazyme \\
P8 & Galactomannan & GB & Locust bean & Sigma \\
P9 & Glucogalactomannan & GS & Spruce & Abo Akademi University \\
P10 & Glucomannan & GK & Konjac & Megazyme \\
P11 & Gum arabic & GA & Acacia tree & Sigma-Aldrich \\
P12 & Inulin & IN & Dahlia tubers & Sigma-Aldrich \\
P13 & Pectin Classic AU202 & AU & Apple & Herbstreith and Fox KG \\
P14 & Pectin Classic CM201 & CM & Citrus & Herbstreith and Fox KG \\
P15 & Pectin, esterified & PC & Citrus & Sigma \\
P16 & Polygalacturonic acid & PG & Orange & Sigma \\
P17 & Rhamnogalacturonan & RG & Soy Bean & Megazyme \\
P18 & Stachyose & ST & Stachys tuberifera & Sigma-Aldrich \\
P19 & Xylan & LG & Beech & Lenzing AG \\
P20 & Xylan & XB & Birch & Sigma \\
P21 & Xyloglucan & XG & Tamarind & Megazyme \\
\hline
\end{tabular}

Table 2 Sample list of cellulose (pulp) samples analyzed

\begin{tabular}{|c|c|c|c|c|}
\hline & Sample & Code & Origin & Producer \\
\hline F01 & Cotton Linters & CL & Cotton & Buckeye \\
\hline F02 & Wheat bran & $\mathrm{BR}$ & Wheat & Unknown \\
\hline \multicolumn{5}{|c|}{ Hardwood pulp } \\
\hline F03 & Bleached Hardwood-Kraft pulp & HK & Birch & Unknown \\
\hline F04 & Bleached Hardwood-Sulfite pulp & HS & Beech & Lenzing AG \\
\hline \multicolumn{5}{|c|}{ Softwood pulp } \\
\hline F05 & Bleached Softwood-Kraft pulp & SK & Spruce $(70 \%)$, pine $(30 \%)$ & Södra \\
\hline F06 & Bleached Softwood-Sulfite pulp & SS & Spruce & Domsjö \\
\hline F07 & Bleached Softwood-TMP & $\mathrm{TM}$ & Spruce & Åbo Akademi University \\
\hline F08 & Bleached Eucalyptus paper pulp_-Kraft pulp & $\mathrm{EC}$ & Eucalyptus & ENCE \\
\hline F09 & $\begin{array}{l}\text { Bleached Eucalyptus paper pulp_-Kraft pulp } \\
\text { e-beam treated* }\end{array}$ & EC-E & Eucalyptus & ENCE \\
\hline F10 & Bleached Hemp paper pulp ECF & $\mathrm{HC}$ & Hemp & Celesa \\
\hline F11 & Bleached Hemp paper pulp ECF-e-beam treated* & HC-E & Hemp & Celesa \\
\hline
\end{tabular}

*Beta-irradiation of $120 \mathrm{kGy}$

sorbitol/mL methanol, $1 \mathrm{~mL}$ ) was added to the samples (methanolysis sample and calibration mix), which were evaporated to dryness in a water bath $\left(50{ }^{\circ} \mathrm{C}\right)$ under nitrogen until dryness and further dried in a vacuum desiccator at room temperature for $30 \mathrm{~min}$. 
Table 3 Sample list of papers analyzed

\begin{tabular}{llll}
\hline No & Sample & Code & Origin \\
\hline F12 & Book 1 (1951) & B1 & \\
F13 & Book 2 (1912) & B2 & \\
F14 & Book 3 (1892) & B3 & B4 \\
F15 & Book 4 (1860) & MB & Mulberry \\
F16 & Mulberry paper & PH & \\
F17 & Paper sample (historical) & RH & \\
F18 & Rag papr (historical) & RM & \\
F19 & Rag paper (modern) & RM-A & \\
F20 & Rag paper (modern)—artificially aged* & RM-E & \\
F21 & Rag paper (modern)—e-beam treated** & & \\
\hline
\end{tabular}

Per(trimethylsilylation) of hydrolysis product mixtures

The derivatization used the procedure by Becker et al. $(2013 a, b))^{31}$ The dried hydrolysates, calibration mixtures, and reference compounds were dissolved in $200 \mu \mathrm{L}$ of pyridine and incubated at room temperature for $30 \mathrm{~min}$. A solution of the silylation catalyst $(1.5 \mathrm{mg} / \mathrm{mL}$ DMAP in pyridine, $200 \mu \mathrm{L})$ and silylation agent $(\mathrm{N}, \mathrm{O}$-bis(trimethylsilyl)trifluoroacetamide containing $10 \%$ trimethylsilyl chloride, $200 \mu \mathrm{L}$ ) was added to the mixture, which was stirred at $70{ }^{\circ} \mathrm{C}$ for $2 \mathrm{~h}$. After cooling to r.t., the derivatized samples were kept at $-20{ }^{\circ} \mathrm{C}$ until analysis.

GC-FID and GC-MS analysis of TMS-derivatized hydrolysis products

The derivatized samples were diluted with ethyl acetate $(600 \mu \mathrm{l})$ and filtered before injection. Aliquots of $0.2 \mu \mathrm{L}$ were injected in splitless mode and analyzed on an Agilent 7890A gas chromatograph coupled with an Agilent 5975C mass selective detector and Agilent GC Sampler 120. GC-FID analysis was performed on a Perkin Elmer Autosystem XL gas chromatograph with analysis parameters based on Sundberg et al. (1996). ${ }^{18}$ Column: HP-1 $(25 \mathrm{~m} \times 0.20 \mathrm{~mm} \times 0.11$ $\mu \mathrm{m}$; J\&W Scientific, Folsom, CA, USA); carrier gas: hydrogen, injector temperature: $250{ }^{\circ} \mathrm{C}$; column flow: $0.8 \mathrm{ml} / \mathrm{min}$, pressure $14 \mathrm{psi}$; oven program: $100{ }^{\circ} \mathrm{C}$ (1 min), $4{ }^{\circ} \mathrm{C} / \mathrm{min}$ to $170{ }^{\circ} \mathrm{C}, 12{ }^{\circ} \mathrm{C} / \mathrm{min}, 300{ }^{\circ} \mathrm{C}$ (7 min); detector temperature: $310^{\circ} \mathrm{C}$. Aliquots of $1 \mu \mathrm{L}$ were injected in split mode (split ratio 1:25).

General GC-MS analysis conditions: Column: HP$5 \mathrm{MS}(30 \mathrm{~m} \times 0.25 \mathrm{~mm} \times 25 \mu \mathrm{m}$; J\&W Scientific,
Folsom, CA, USA); carrier gas: helium, MS: EI mode, $70 \mathrm{eV}$, source pressure: $1.13 \times 10^{-7} \mathrm{~Pa}$, purge flow: $36.3 \mathrm{ml} / \mathrm{min}, 0.6 \mathrm{~min}$; source temperature: $230{ }^{\circ} \mathrm{C}$. Scan range was set from 43 to $950 \mathrm{Da}$. Parameters for analysis of products from acidic methanolysis: injector temperature: $140{ }^{\circ} \mathrm{C}\left(30{ }^{\circ} \mathrm{C} / \mathrm{min}\right.$ to $\left.260{ }^{\circ} \mathrm{C}\right)$; column flow: $0.9 \mathrm{ml} / \mathrm{min}$; oven program: $140{ }^{\circ} \mathrm{C}$ (1 min), $4{ }^{\circ} \mathrm{C} / \mathrm{min}$ to $210{ }^{\circ} \mathrm{C}$, then $30^{\circ} \mathrm{C} / \mathrm{min}$, $260{ }^{\circ} \mathrm{C}$ (5 min); inlet pressure $78.361 \mathrm{kPa}$.

Parameters for analysis of products from sulfuric acid hydrolysis: injector temperature: $150{ }^{\circ} \mathrm{C}\left(30{ }^{\circ} \mathrm{C} /\right.$ min to $260{ }^{\circ} \mathrm{C}$ ); column flow: $0.9 \mathrm{ml} / \mathrm{min}$; oven program: $120{ }^{\circ} \mathrm{C}(2 \mathrm{~min}), 5^{\circ} \mathrm{C} / \mathrm{min}$ to $230{ }^{\circ} \mathrm{C}$, then $20{ }^{\circ} \mathrm{C} / \mathrm{min}, \quad 260{ }^{\circ} \mathrm{C} \quad(10 \mathrm{~min})$; inlet pressure $78.361 \mathrm{kPa}$.

Peak identification and quantification

Peak assignment, data acquisition, and quantification of hydrolysis or methanolysis products were performed with MSD Chemstation E.2.01.1177 (Agilent Technologies, USA). Peaks were assigned by comparing their retention times and mass spectra with those of corresponding reference compounds (Fig. 1). Calibration factors were determined from the carbohydrate standard solution after sulfuric acid hydrolysis or acidic methanolysis by the ratio between the total area of the different peaks of one analyte and the area of the sorbitol peak. The calibration factor of 4-OMeGlcA, which is not commercially available as pure standard, was approximated to be the same as for GlcA. Samples were analyzed in quadruplicate, and values deviating from the average by more than $15 \%$ were regarded as outliers. All the results were based on masses of dried and freeze-dried material. 


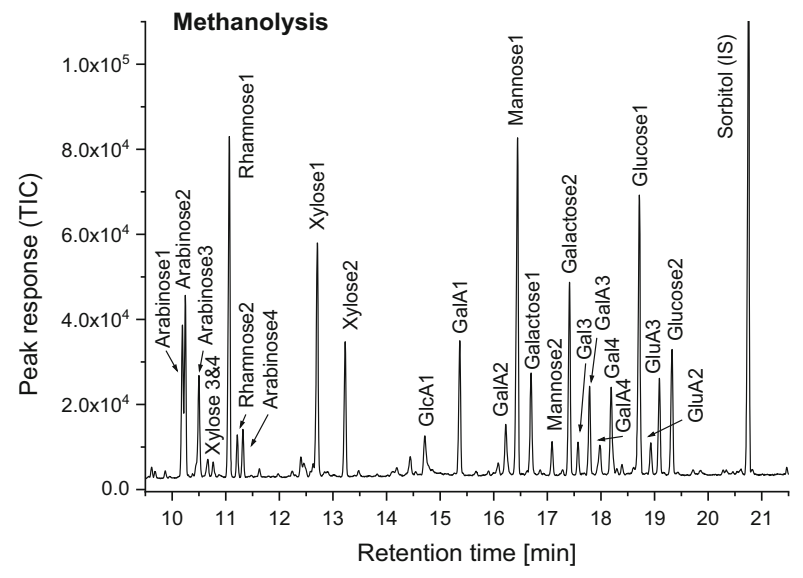

Fig. 1 Left: acidic methanolysis of a carbohydrate mixture containing arabinose, rhamnose, xylose, galactose, glucose, mannose, galacturonic acid (GalA), and glucuronic acid (GlcA);

\section{Solid-state NMR}

All solid-state NMR experiments were performed on a Bruker Avance III HD 400 spectrometer (resonance frequency of ${ }^{1} \mathrm{H}$ of $400.13 \mathrm{MHz}$, and ${ }^{13} \mathrm{C}$ of $100.61 \mathrm{MHz}$, respectively), equipped with a $4 \mathrm{~mm}$ dual broadband CP/MAS probe. The pulp/paper samples were swollen in deionized water overnight before measurement. ${ }^{13} \mathrm{C}$ spectra were acquired by using the TOSS (total sideband suppression) sequence at ambient temperature with a spinning rate of $5 \mathrm{kHz}$, a cross-polarization (CP) a contact time of $2 \mathrm{~ms}$, a recycle delay of $2 \mathrm{~s}$, SPINAL $64{ }^{1} \mathrm{H}$ decoupling and an acquisition time of $43 \mathrm{~ms}$. Chemical shifts were referenced externally against the carbonyl signal of glycine with $\delta=176.03 \mathrm{ppm}$. The acquired FIDs were apodized with an exponential function $(\mathrm{lb}=1$ $\mathrm{Hz}$ ) before Fourier transformation. Peak fitting was performed with the Dmfit program. The spectral deconvolution and assignment to cellulose subspecies was performed by spectral fitting according to the model and method of Larsson et al. (1997). ${ }^{7}$

\section{GPC analysis of cellulose samples}

The used protocol is based on Potthast et al. (2015). Samples were characterized by means of the weightaveraged molecular mass $\left(\mathrm{M}_{\mathrm{w}}\right)$ obtained from the molecular mass distribution. The cellulosic pulp and paper samples were dissolved in $N, N$-dimethylacetamide containing $9 \%$ of lithium chloride (w/v), for

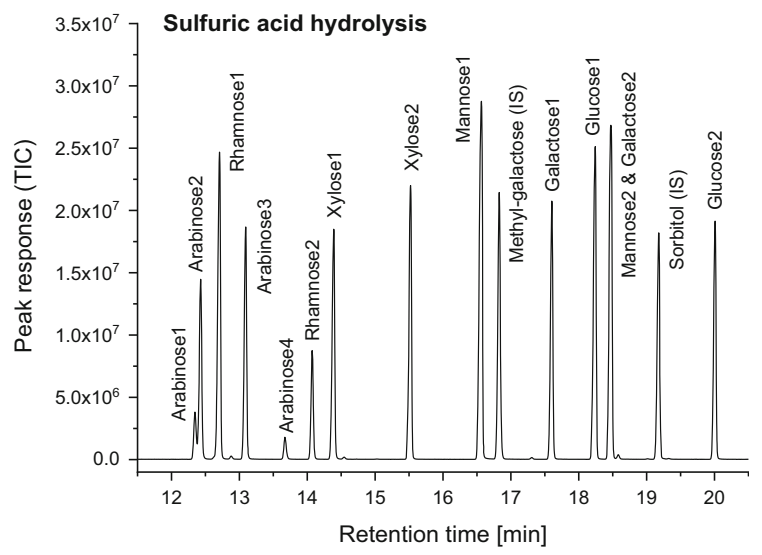

right: sulfuric acid hydrolysis of a carbohydrate mixture containing arabinose, rhamnose, xylose, galactose, glucose, and mannose

the solvent system see Chrapava et al. (2003). The measurement was performed on the GPC system with fluorescence detector (TSP FL2000), multiple-angle laser light scattering detector (Wyatt Dawn DSP with $\operatorname{argon}$ ion laser $\left.\left(\lambda_{0}=488 \mathrm{~nm}\right)\right]$ and refractive index detector (Shodex RI-71). Separation was performed on a set of four consecutive PLgel mixed-ALS columns $(20 \mu \mathrm{m}, 7.5 \times 300 \mathrm{~mm}$, Varian/Agilent $)$. $\mathrm{N}, \mathrm{N}$-Dimethylacetamide containing $0.9 \%$ lithium chloride $(\mathrm{w} / \mathrm{v})$ was used for mobile phase. The system was operated at a flow rate of $1.0 \mathrm{ml} / \mathrm{min}$ with an injection volume of $100 \mu \mathrm{L}$. Data evaluation was performed with standard Chromeleon 4, Astra 4.73, and GRAMS/32 software packages.

\section{Results and discussion}

\section{Acidic methanolysis}

Acidic methanolysis proceeded neatly with all tested polysaccharides (Fig. 2) and gave recoveries between $55 \%$ and $102.2 \%$ of released sugar units, with an average of $83 \%$, which can be regarded as satisfactory. From a conservation science perspective, this is an important result as it confirms that hemicelluloses and auxiliaries often used in conservation treatments can be detected and reliably reported by the method. Only inulin, although completely consumed and solubilized, gave a very poor recovery rate of released carbohydrates of $4.3 \%$. Inulin consists of $\beta-1 \rightarrow 2-$ 

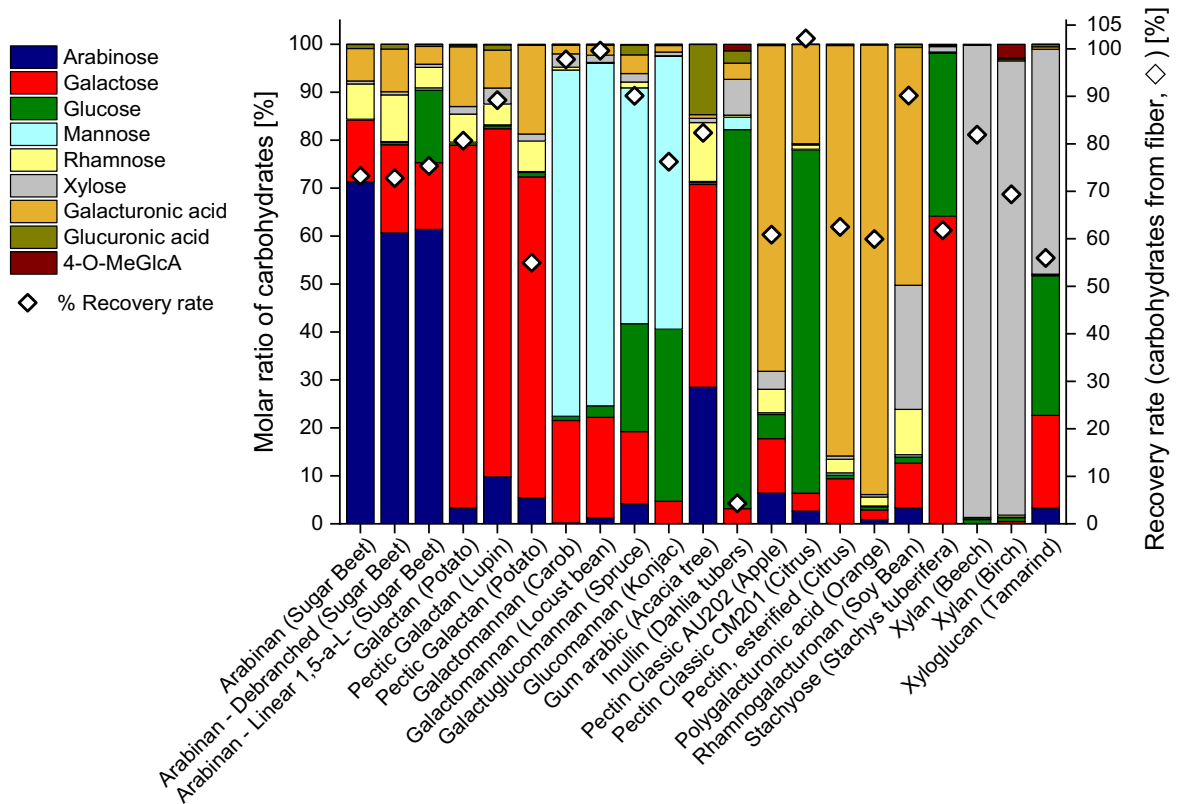

Fig. 2 Carbohydrate composition of different polysaccharides, obtained by acidic methanolysis and GC-FID or GC-MS analysis. Molar ratio in \% of the total sugar amounts (columns)

linked fructofuranose units with a terminal $\alpha-1 \rightarrow 2$ linked glucose unit. While fructose is degraded to furanoid dehydration products during methanolysis, the terminal glucose units are enriched in the mixture and only these are reported.

The primary monosaccharides identified with methanolysis in cellulose samples were glucose, xylose, and mannose, followed by arabinose and galactose (Fig. 2). While glucose originates mainly from cellulose, all other monosaccharides come from hemicelluloses contained (pulps) and/or added auxiliaries (paper). Hydrolysis of these sources (hemicelluloses and additives) was complete as was demonstrated by prolonged reaction times which did not further increase the yield of the contained monosaccharide constituents. However, as expected, the overall recovery rates of released carbohydrates for cellulose-based samples were much lower than in the case of the non-cellulose polysaccharide samples, because a major part of the cellulose materials, mainly the crystalline and other "recalcitrant" regions, are not hydrolyzed (see above).

2. Sulfuric acid hydrolysis ("total hydrolysis") and recovery rate of released carbohydrates in $\%(\diamond)$. For more information about the polysaccharide samples see Table 1

Sulfuric acid hydrolysis of the polysaccharide samples provided the monosaccharide patterns shown in Fig. 4. A comparison with the data from methanolysis (Fig. 2) showed the main components to be emphasized with values around $90 \%, c f$. for instance the high arabinose values in arabinans or the high galactose values in galactans. While also methanolysis reported these monosaccharides to be the main constituents (contents between 60 and 70\%), it also showed diverse minor constituents in the single-digit percentage range, such as rhamnose, galactose, glucose and galacturonic acid for arabinans or arabinose, rhamnose, glucose and galacturonic acid for galactans. Sulfuric acid hydrolysis evidently suppressed those minor components. The recovery values of released monosaccharides after sulfuric acid hydrolysis ranged from 0.22 to $69 \%$, with an average of $39 \%$, which was only roughly half of the methanolysis value $(83 \%)$. The highest recovery values were seen for galactomannan, glucomannan, and xylan, which corresponded to the methanolysis results. The lower recovery and the suppression of minor components are due to the harsh hydrolysis conditions which entail high amounts and large numbers of byproducts, in particular furanoid condensation/dehydration products. Note that sulfuric acid hydrolysis had been 
introduced for cellulosic materials where the high acidity and the harsh environment is necessary to bring also the recalcitrant higher-order domains to reaction. But these conditions were obviously not optimal for the more labile non-cellulosic polysaccharides studied as the complete solubilization was achieved at the expense of increased byproduct formation and loss of information. This was especially evident in the case of uronic acids: none of the five calibrated uronic acids (galacturonic, glucuronic, 4- $O$-methyl-glucuronic, mannuronic and guluronic acids, the latter two being contained in alginates but not covered in the present study) was observed after sulfuric acid hydrolysis of polysaccharides, not even in traces (Fig. 4), while they were reliably reported by methanolysis (Figs. 2 and 3). These sugar acids undergo decarboxylation and subsequent degradation under the strongly acidic and harsh conditions of sulfuric acid treatment.

A drastic example in this regard was polygalacturonic acid, a pectin: the galacturonic acid content of $56.8 \%$ (methanolysis) shrank to zero according to sulfuric acid hydrolysis. Similarly, gum Arabic with $14 \%$ of 4-O-methyl-glucuronic acid (methanolysis) appeared to contain none of this sugar acid according to sulfuric acid hydrolysis. This virtually forces a cautionary remark from the viewpoint of cellulose conservation: gum Arabic and some pectins have been traditionally used for paper stabilization and conservation treatments. If such papers are examined according to the sulfuric acid hydrolysis method, the presence of such auxiliaries is simply concealed, and it is likely that false conclusions will be drawn about the provenance of the paper, previous conservation treatments and future measures. For such studies, one must resort to the methanolysis method. The focus of interest in such cases is obviously on the additives and on minor components, which are monitored correctly by methanolysis, but not on the-rather obviouscellulose/glucose content, which would be better measured by total hydrolysis.

The sulfuric acid hydrolysis (total hydrolysis) of different cellulose samples (Fig. 5) showed higher recovery rates compared to acidic methanolysis (Fig. 3) because the sulfuric acid hydrolysis affected not only the amorphous cellulose fraction but also the crystalline fraction, and also compared to the sulfuric acid hydrolysis of the polysaccharides (Fig. 4) because the largest product component-glucose from cellulose-was more resistant to side reactions and byproduct formation than many of the other monosaccharide units. Recovery rates ranged between 51.9 and $72.5 \%$, except softwood thermomechanical pulp $(34.5 \%)$ and wheat bran $(40.3 \%)$, see Fig. 5. The molar ratios of glucose were high and ranged from 39.6 to $100 \%$, followed by xylose (up to $40.3 \%$ ), and mannose (up to $18.9 \%$ ). In some samples rhamnose
Fig. 3 Carbohydrate composition of cellulosic pulp and paper samples, obtained by acidic methanolysis and GC-FID or GC-MS analysis. Molar ratio in $\%$ of the total sugar amount (columns) and recovery rate of released carbohydrates in \% $(\diamond)$. For more information about the cellulose samples see Tables 2 and 3
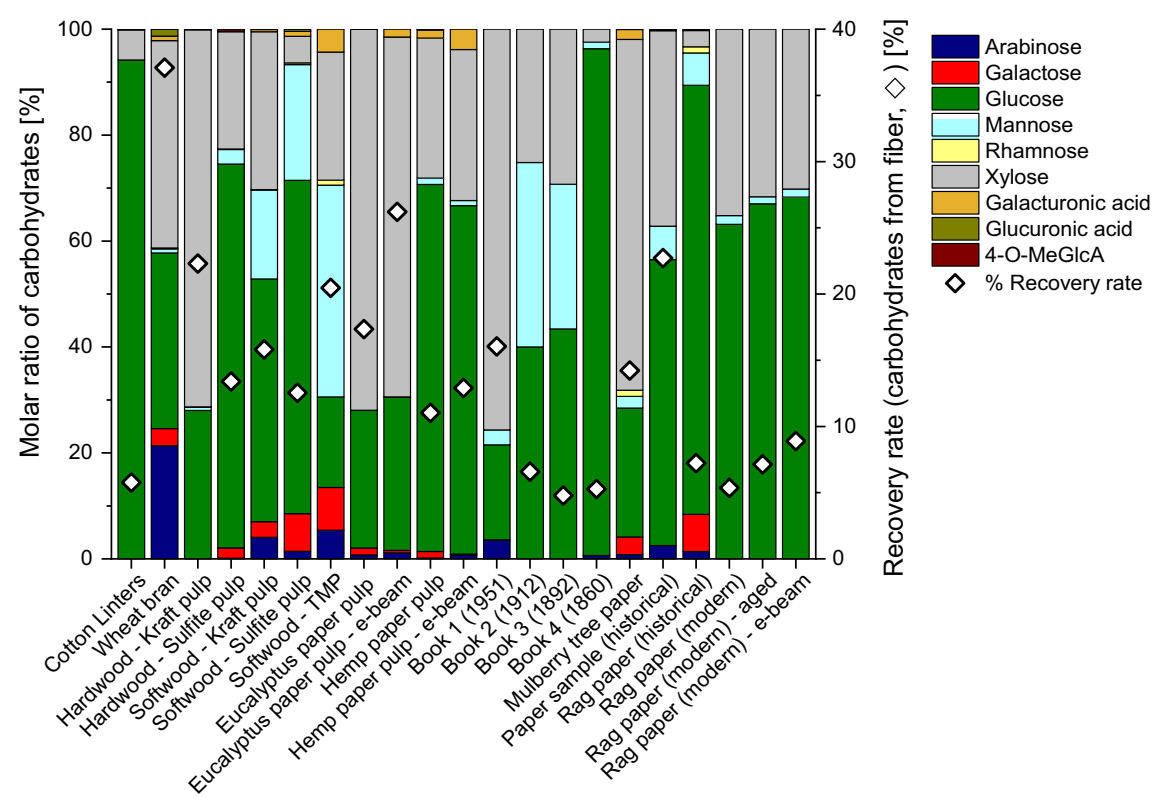

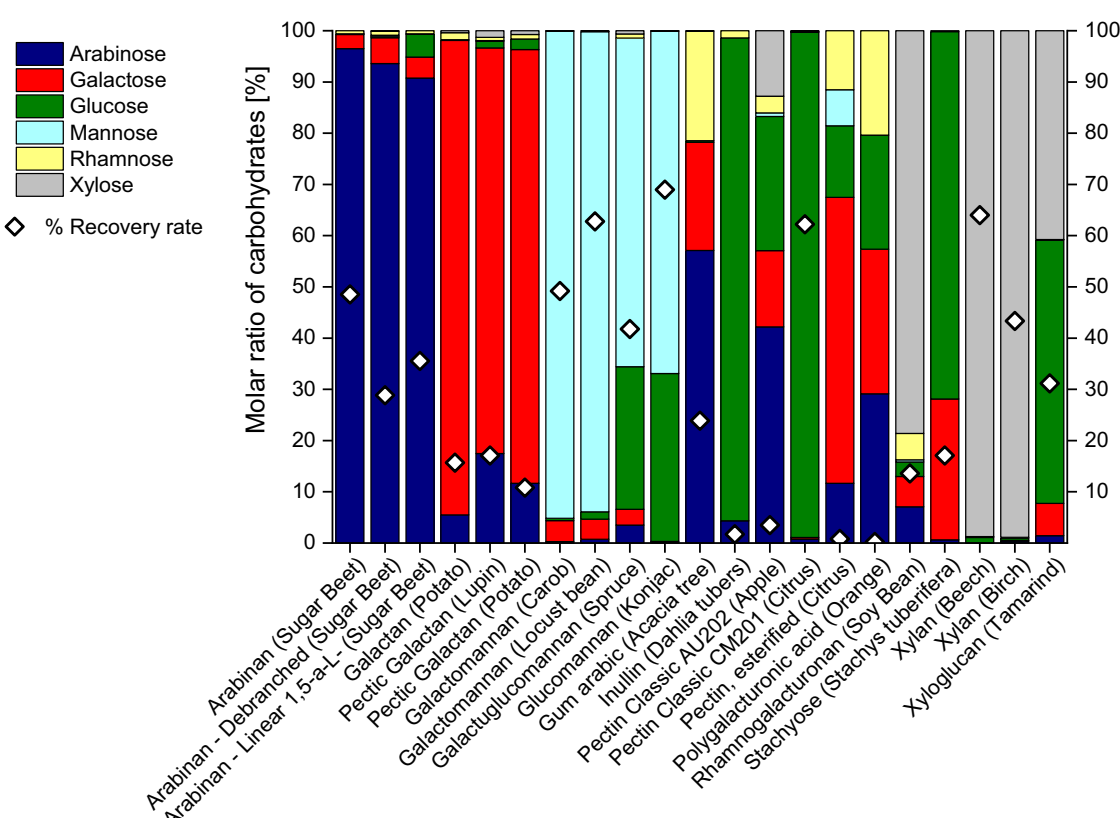

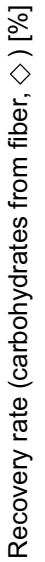

Fig. 4 Carbohydrate composition of polysaccharide samples, obtained by sulfuric acid hydrolysis (total hydrolysis) and GCMS analysis. Molar ratio in \% of the total sugar amount (columns) and recovery rate of released carbohydrates in \% $(\diamond)$. For further information about the polysaccharide samples see Table 1
Fig. 5 Carbohydrate composition of cellulose samples, expressed as molar ratio in $\%$ of the total sugar amount (columns) and recovery rate of released carbohydrates in $\%(\diamond)$ by sulfuric acid hydrolysis and GC-MS analysis. Further information about the samples is shown in Tables 2 and 3
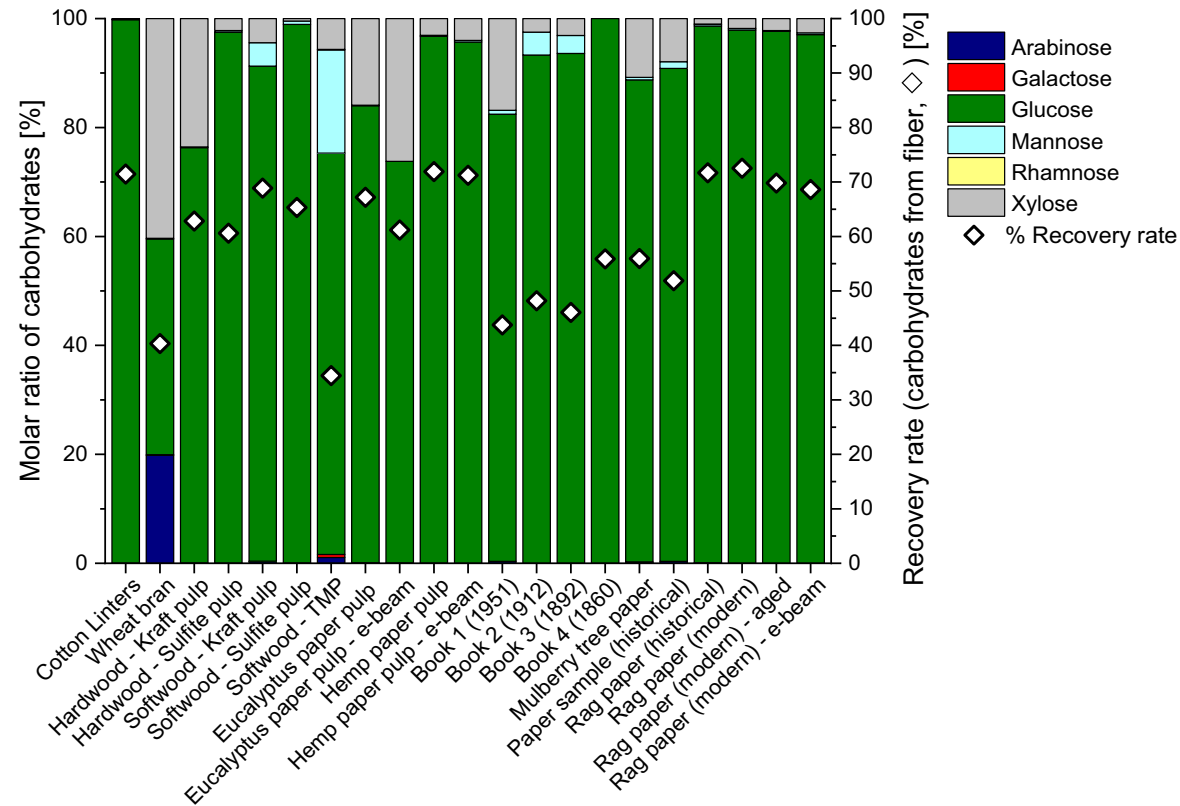

and galactose were reported to be present in concentrations below one percent. Arabinose and uronic acids were not found.
This "simplicity" of the monosaccharide profiles was in complete agreement with the results from polysaccharide total hydrolysis (Fig. 4): several components were suppressed (more correctly: not detected 
as they were not present due to side reactions) so that the composition appeared less diverse than it actually was (Fig. 3). Although the predominance of glucose in cellulosic substrates is not surprising, the failure to report many minor components from hemicelluloses and pectins is certainly a major drawback of the method. Again, especially the uronic acids were affected, and the destruction of low-content carbohydrates led to a loss of information compared to acidic methanolysis (cf. Figure 3). Incomplete hydrolysis and presence of oligomers was excluded because no signals of disaccharides and trisaccharides were present in GC, and no higher oligomers were detected by HPTLC. The fractions of lipophilic extractives, proteins, and (residual) lignin, and inorganic components were not considered in this study, which influences the recovery values negatively, albeit only to a small extent in the low single-digit percent range.

The acid concentrations, reaction temperatures and processing times of the two-step sulfuric acid hydrolysis method applied in this study was optimized according to Bose et al. (2009) and were adapted for GC/MS analysis. Cellulose crystallinity, the ill-defined term of hornification and the lignin composition of cellulosic samples influence the hydrolysis rates in this procedure (Wijaya et al. 2014) and thus indirectly also the rate and prominence of side reactions. The presence of lignin and condensation/dehydration products from hemicellulose on the surface of cellulose crystallites can negatively affect the cellulose hydrolysis rate (Bhandari et al. 1984; Singh et al. 1984; Zhang et al. 2007). Although the conditions for the two-step sulfuric acid hydrolysis used are generally less harsh than other commonly applied hydrolysis conditions (Bose et al. 2009), the longer reaction times needed to completely hydrolyze such recalcitrant substrates mean at the same time strongly increased degradation of already liberated monosaccharides (Girisuta et al. 2007; Morales et al. 2014).

3. Application of the hydrolysis methods to e-beaming and artificial aging

$\beta$-Irradiation (e-beam) treatment is generally used to modify chemical and physical properties of cellulosecontaining materials (Henniges et al. 2012, 2013; Driscoll et al. 2009; Sarosi et al. 2020). It has been proposed as pre-treatment of renewable lignocellulosic resources to improve monosaccharide yield for bioethanol production (Postek et al. 2018; Chung et al. 2012; Sundar et al. 2014) or nanocellulose production (Kim et al. 2016; Leskinen et al. 2017; Eo et al. 2016). It was also used as conservation treatment and to clean stained or microbially infested papers (Chosdu et al. 1993; Chmielewska-Śmietanko 2018; Driscoll et al. 2009) and to make papers amenable to reinforcement by synthetic polymer grafts (Kumar and Tumu 2019; Driscoll et al. 2009). Both applications made it especially interesting from the viewpoint of paper conservation in the field of preservation of cultural heritage. The reduction of crystallinity by e-beam radiation has been shown to become evident at doses above $100 \mathrm{kGy}$ (Driscoll et al. 2009; Chung et al. 2012). In our study, paper pulps (eucalyptus and hemp) and rag papers were exposed to e-beam irradiation at $60 \mathrm{kGy}$ or $120 \mathrm{kGy}$ (see Table 2) to find out whether the treatment would have any effects on the results of the two hydrolysis methods.

The sulfuric acid hydrolysis of e-beam treated pulps indicated a minor loss of carbohydrate yield $(-3.0 \%$ for eucalyptus, $-0.9 \%$ for hemp and about $-2.0 \%$ for rag papers), see Fig. 6. The glucose yield stayed nearly constant (except a yield loss of $4.2 \%$ in eucalyptus), and also the xylose yield remained largely unchanged. The outcome was drastically different for the acidic methanolysis, however. Methanolysis reported an increase of the total carbohydrate yield by $51.3 \%$ for eucalyptus pulp, $16.9 \%$ for hemp pulp, and $66.0 \%$ for the rag paper. These differences were indeed massive and much larger than expected. Both the glucose yield and the xylose yield increased significantly (glucose: $+64.9 \%,+11.3 \%,+77.9 \%$ and xylose $+42.2 \%,+26.9 \%,+45.4 \%$ for eucalyptus pulp, hemp pulp and rag paper, respectively), see Fig. 6. Obviously, the e-beam treatment made the materials more accessible to hydrolysis, i.e. it decreased the fraction of reluctant, hard-to-hydrolyze, crystalline fractions. This effect was well reported by the acidic methanolysis method, reflected by a significant gain in carbohydrate yield, which was mainly caused by the gain in glucose yield that came from the cellulose regions now made accessible. In the sulfuric acid system, the yield gain was overcompensated by side reactions, which became even more dominant when more easily hydrolyzable carbohydrate material was present, so that the overall yield stayed constant or even decreased. This result should be kept in mind for studies of the effects of irradiation on cellulosics. An 


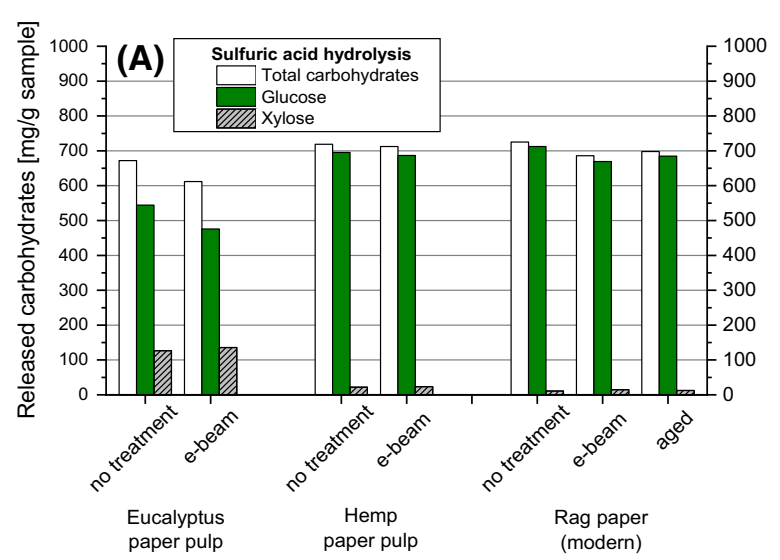

Fig. 6 Released carbohydrates (total amount, glucose and xylose) of untreated, $\beta$-irradiated and artificially aged cellulose samples. Conditions of e-beam treatment: $120 \mathrm{kGy}$ for

evaluation solely based on total hydrolysis data would provide a largely faulty picture.

Solid-state ${ }^{13} \mathrm{C}$ NMR provided only weak support for significant structural changes brought about by $\beta$ irradiation. Evaluated by deconvolution of the ordered (86-92 ppm) and less ordered (80-86 ppm) C4-region (Maunu et al. 2000; Nocanda et al. 2007; Zuckerstätter et al. 2009), the percentages of cellulose I $\alpha$, cellulose I $\beta$, "paracrystalline" cellulose, accessible and inaccessible fibril surface and hemicellulose changed less than $2 \%$, see the Supporting Information. It is understandable that the molecular effects of e-beam treatment-mainly radical processes causing chain cleavage and oxidation of near-surface regions with oxygen access-manifest themselves upon swelling, dissolution or chemical modification, but not through such large changes in the largely immobile solid-state structure that they would be detectable by NMR.

In contrast to solid-state NMR, gel permeation chromatography was able to clearly demonstrate the effect of the $\beta$-irradiation. A rather pronounced chain cleavage was seen with a significant drop of the weight-averaged molecular mass in the e-beam treated samples (eucalyptus paper pulp: $-88.1 \%$; hemp paper pulp: $-87.4 \%$; rag paper: $-83.3 \%$ ), see Fig. 7. This is in agreement with the literature which showed similar Mw-loss effects (Saeman et al. 1952; Henniges et al. 2011, 2012, 2013; Hwang et al. 2021).

Accelerated aging, often also called "artificial" aging, is a frequently used approach to simulate natural ageing (Zou et al. 1996; Kato et al. 1999; Ali

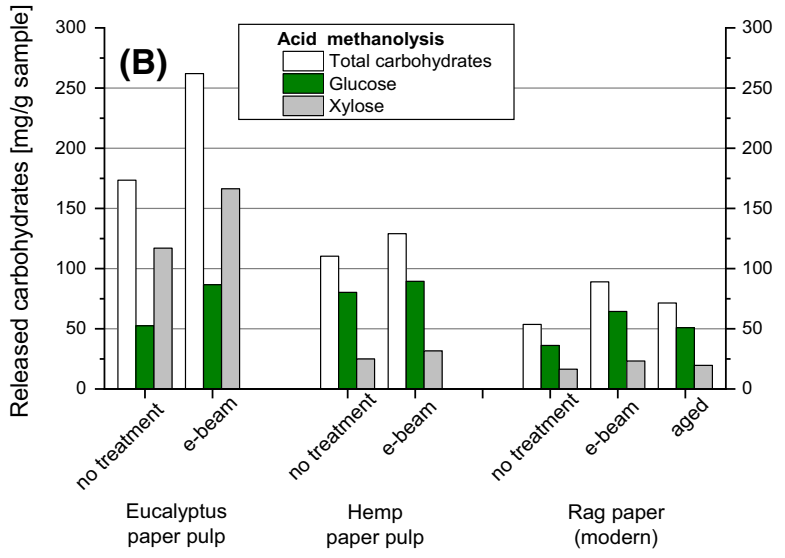

eucalyptus and hemp paper pulps, $60 \mathrm{kGy}$ for rag paper. Left (a): sulfuric acid hydrolysis (total hydrolysis); right (b): methanolysis

et al. 2001; Zervos 2010) and to predict the long-term efficiency of conservation treatments. The ageing process was reported to induce structural changes within the paper samples, in particular to change the crystallinity of cellulose. Contradictory opinions are found in the literature with regard to the direction of the crystallinity change in thermally-aged celluloses, with both decrease and increase having been reported (Henniges et al. 2011; Sandy et al. 2010). The impact of environmental parameters on the ageing of paper samples, such as temperature, pressure, air moisture content, presence of oxygen or UV irradiation, has been studied (Baranski 2002; Zou et al. 1996) and degradation kinetic models for artificial ageing processes of papers have been proposed (Emsley and Stevens 1994; Selli et al. 1998, Calvini and Gorassini 2006, Calvini et al. 2008; Kacik et al. 2008). These external parameters, in combination with paperdependent, internal factors, such as acidity, water content or additive contents (e.g. alum or calcium carbonate), are the key factors influencing the rate of the aging process which, often described by the general term "paper degradation", is mostly analytically evaluated by the shortening of the cellulose chains, e.g. an Mw loss, or by the accelerated formation of chromophores, e.g. pronounced yellowing, brightness reversion (Korntner et al. 2015; Rosenau et al. 2004) or oxidized functional groups (Ahn et al. 2019; Potthast et al. 2005).

When looking at artificial aging from the perspective of hydrolysis analysis and monosaccharide 


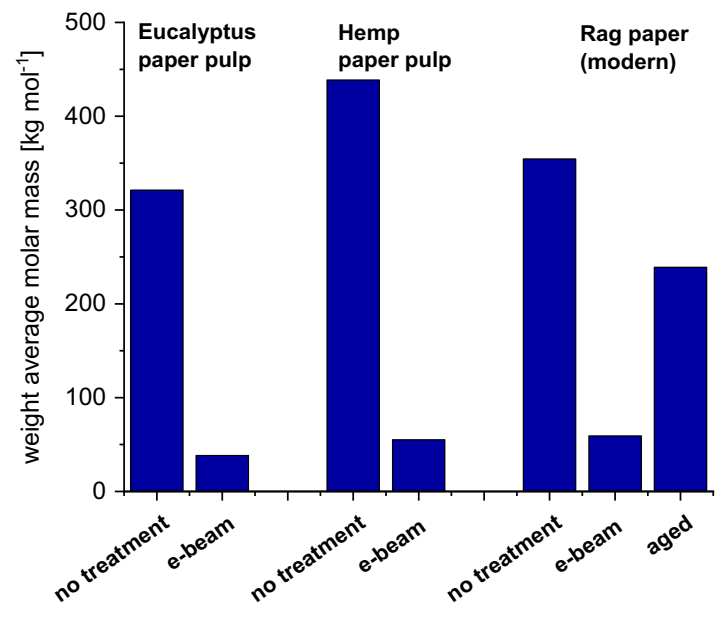

Fig. 7 Left: Effect of different treatments (electron beam irradiated (e-beam) and artificially aged cellulose samples (eucalyptus and hemp paper pulps: $120 \mathrm{kGy}$, and rag paper:

composition, some similarities can be stated with the $\beta$-irradiation treatment. Upon accelerated aging, the total carbohydrate yield of rag paper slightly decreased by sulfuric acid (total) hydrolysis $(-3.7 \%)$, but significantly increased according to the acid-catalyzed methanolysis approach $(+33.2 \%)$, as shown in Fig. 6. With regard to glucose recovery, the values were $-3.9 \%$ for total hydrolysis and + $40.6 \%$ for methanolysis. It was evident that the aging procedure increased the accessibility upon hydrolysis, and since this increase was parallel to the increased hydrolytic availability of glucose it must originate from a better access to and destruction of the previously recalcitrant crystalline regions. This was supported by the GPC results: artificial ageing effected an Mw loss in the rag paper of $-32.6 \%$, which is very significant, although not as severe as in the case of e-beam treatment (Fig. 7). This is understandable as the energy input during $\beta$-irradiation was much higher, and the subsequent effects, such as radical processes and chain cleavage, consequently more pronounced.

It should be mentioned that our results are somewhat contradictory to those by Sandy et al. (2010) who observed an increase of the crystalline cellulose fraction after ageing experiments, which has later been generalized (Menart et al. 2011). The aging procedure used involved a hydrochloric acid pretreatment of the paper samples prior to the actual ageing process. It is true that treatment of celluloses with gaseous $\mathrm{HCl}$ can increase the crystallinity

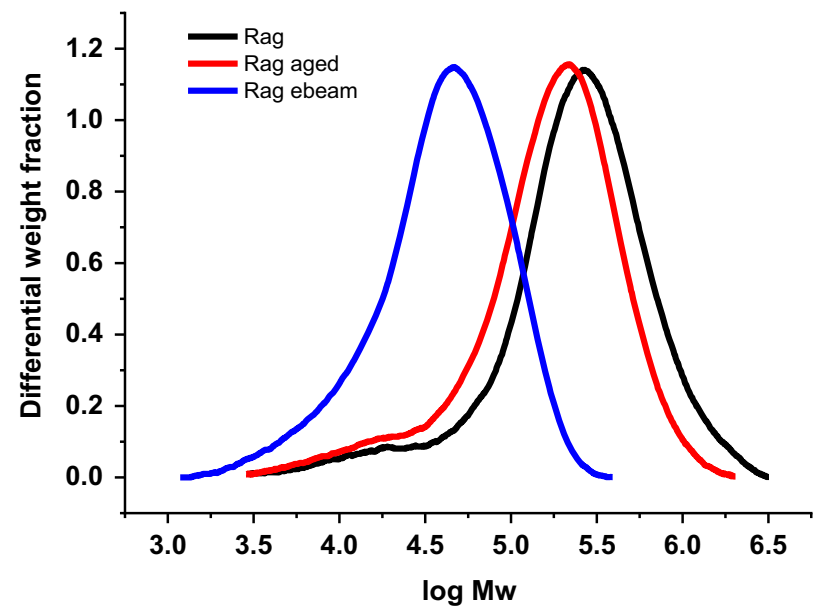

$60 \mathrm{kGy}$ ) on weight-average molar mass. Right: Molar mass distribution of treated rag papers

(Kontturi et al. 2016), but a treatment with aqueous $\mathrm{HCl}$ has the opposite effect. The acid pre-treatment followed by the thermal aging generates conditions similar to acid-catalyzed methanolysis. Accessible parts are so severely degraded that they are not recognized as amorphous cellulose and hemicellulose anymore, which results in an apparent increase of crystallinity. This becomes obvious when the monosaccharide yield and GPC data are evaluated as in our study.

\section{Conclusions}

The two hydrolysis methods studied, total hydrolysis with sulfuric acid and methanolysis represent a useful analytical tool for determination of the monosaccharide composition of polysaccharide and cellulose samples in combination with structural changes of the material. The released monosaccharide compounds are quantified by gas chromatographic analysis (GC-MS and GC-FID). Especially the combination of both approaches proved to be useful.

Sulfuric acid hydrolysis is the one of the two methods that completely dissolves and consumes the sample material and also captures the crystalline regions of cellulose, therefore also the common denomination "total hydrolysis". However, to achieve this full conversion requires rather harsh conditions to be used, so that it comes at the expense of side 
reactions and degradation of already hydrolyzed/solubilized material. In heterogeneous materials, easily hydrolyzed polysaccharides and readily accessible domains will react fast and soon release their monosaccharides into the harsh medium, where they may undergo side reactions and degradation, while the hard-to-hydrolyze regions may not yet have reacted at all. This becomes a severe problem if non-cellulosic polysaccharides are studied. In particular, glucuronic acids are degraded and not found in the product mixtures, the same is true for ketoses and oxidized monosaccharides with additional carbonyl groups.

Methanolysis as the hydrolysis method behaves in the opposite way. It applies quite mild conditions so that side reactions and degradation of release monosaccharides hardly occur, but it does not hydrolyze the ill-accessible, crystalline regions of cellulose. All monosaccharides are converted into their methyl glucosides, and isomerization causes the appearance of up to four peaks $(\alpha / \beta$-furanoses and $\alpha / \beta$ pyranoses). Although this increases chromatographic crowding for GC separations, it does not actually mean a drawback, since the risk of complete co-elution is lowered and, as the peak ratio between the isomers is constant for a monosaccharide, quantification can be based on and controlled by more than one peak. As a big plus, side reactions and degradation are minimal. Also uronic acids, which are converted in situ to their methyl esters, can be reliably monitored. Thus, both methods have their pros and cons, and their use must be selected according to the particular sample or analytical problem.

With regard to cellulose conservation science, acidcatalyzed methanolysis was clearly the more valuable of the two approaches. The presence of commonly applied auxiliaries on (historic) paper samples, such as Gum Arabic or pectins, with their high uronate contents, is truthfully reported by methanolysis, but not at all by sulfuric acid hydrolysis which is unsuitable for uronic acid detection. Apart from the conservation aspect, this deficiency of sulfuric acid hydrolysis might also become important if the method is applied to TEMPO-oxidized cellulosic materials, such as the frequently utilized TEMPO-oxidized cellulose nanofibrils or polyglucuronic acids, or alginates (mannuronic and guluronic acids). In these cases, only methanolysis can be used for monosaccharide analysis as the sulfuric acid alternative fails to capture uronic acids and gives grossly erroneous results. Similarly, the minor contents of oxidized groups (carbonyl and carboxyl) in oxidatively damaged cellulosic would never by correctly reported by the total hydrolysis method.

Also with respect to paper conservation treatments, such as $\beta$-irradiation (e-beam treatment) and accelerating aging, acid-catalyzed methanolysis was superior to its $\mathrm{H}_{2} \mathrm{SO}_{4}$ counterpart. The latter indirectly showed a decrease in crystallinity, for both methods, but especially for $\beta$-irradiation, because of a faster hydrolysis reaction and a decrease of the total monosaccharide yield due to more side reactions. Methanolysis, on the other hand, showed a significantly boosted monosaccharide yield (mainly due to a gain of glucose from cellulose). These results were independent of the sample type. It became clear that both treatments significantly increased the accessibility and the reactivity upon hydrolysis. This is accompanied (or caused) by a drastic loss of molecular weight as seen by GPC. GPC was well able to report the changes caused by the treatments, as was methanolysis, whereas solid-state NMR showed very little spectral change.

The $\beta$-irradiation treatment improved carbohydrate yield and polysaccharide accessibility in cidic hydrolysis-probably this is equally true for enzyme treatments. This makes the method interesting as pretreatment option for biomass feedstocks in biofuel conversion. In conservation science, the intended benefits, e.g. sterilization or elimination of pest infestation, must be balanced with the obvious negative effect of the structural changes and Mw loss. The effect of accelerated aging was clearly seen by the methanolysis approach - and fully agreed with GPC results. However, it remains to be seen whether these effects are the same as those seen in natural aging of paper materials, and whether the accelerated aging is thus a suitable mimic of the natural process.

Acknowledgments The financial support by the Austrian Biorefinery Center Tulln (ABCT) and by an STSM grant from the European COST B21 Action FP0901 (COST-STSMFP0901-9940) is gratefully acknowledged.

Funding Open access funding provided by University of Natural Resources and Life Sciences Vienna (BOKU).

\section{Declarations}

Conflict of interest The authors declare that they have no conflict of interest. 
Open Access This article is licensed under a Creative Commons Attribution 4.0 International License, which permits use, sharing, adaptation, distribution and reproduction in any medium or format, as long as you give appropriate credit to the original author(s) and the source, provide a link to the Creative Commons licence, and indicate if changes were made. The images or other third party material in this article are included in the article's Creative Commons licence, unless indicated otherwise in a credit line to the material. If material is not included in the article's Creative Commons licence and your intended use is not permitted by statutory regulation or exceeds the permitted use, you will need to obtain permission directly from the copyright holder. To view a copy of this licence, visit http://creativecommons.org/licenses/by/4.0/.

\section{References}

Ahn K, Zaccaron S, Zwirchmayr NS, Hettegger H, Hofinger H, Bacher M, Henniges U, Hosoya T, Potthast A, Rosenau T (2019) Yellowing and brightness reversion of celluloses: $\mathrm{CO}$ or $\mathrm{COOH}$, who is the culprit? Cellulose 26:429-444

Ali M, Emsley AM, Herman H, Heywood RJ (2001) Spectroscopic studies of the ageing of cellulosic paper. Polymer 42(7):2893-2900

Amelung W, Cheshire MV, Guggenberger G (1996) Determination of neutral and acidic sugars in soil by capillary gasliquid chromatography after trifluoroacetic acid hydrolysis. Soil Biol Biochem 28(12):1631-1639

Barański A (2002) Ageing kinetics of cellulose and paper. Restaurator 23(2):77-88

Becker M, Zweckmair T, Forneck A, Rosenau T, Potthast A, Liebner F (2013a) Evaluation of different derivatisation approaches for gas chromatographic-mass spectrometric analysis of carbohydrates in complex matrices of biological and synthetic origin. J Chromatogr A 1281:115-126

Becker M, Liebner F, Rosenau T, Potthast A (2013b) Ethoximation-silylation approach with expanded retention index (ERI) for mono- and disaccharide analysis by GC/MS. Talanta 115:642-651

Bertaud F, Sundberg A, Holmbom B (2002) Evaluation of acid methanolysis for analysis of wood hemicelluloses and pectins. Carbohydr Polym 48(3):319-324

Bhandari N, Macdonald DG, Bakhshi NN (1984) Kinetic studies of corn stover saccharification using sulphuric acid. Biotechnol Bioeng 26(4):320-327

Black GE, Fox A (1996) Recent progress in the analysis of sugar monomers from complex matrices using chromatography in conjunction with mass spectrometry or stand-alone tandem mass spectrometry. J Chromatogr A 720(1-2):51-60

Bose SK, Barber VA, Alves EF, Kiemle DJ, Stipanovic AJ, Francis RC (2009) An improved method for the hydrolysis of hardwood carbohydrates to monomers. Carbohydr Polym 78(3):396-401

Calvini P, Gorassini A (2006) On the rate of paper degradation: lessons from the past. Restaurator 27(4):275-290
Calvini P, Gorassini A, Merlani AL (2008) On the kinetics of cellulose degradation: looking beyond the pseudo zero order rate equation. Cellulose 15(2):193-203

Chambers RE, Clamp JR (1971) Assessment of methanolysis and other factors used in analysis of carbohydrate-containing materials. Biochem J 125(4):1009

Chmielewska-Śmietanko D, Gryczka U, Migdał W, Kopeć K (2018) Electron beam for preservation of biodeteriorated cultural heritage paper-based objects. Rad Phys Chem 143:89-93

Chosdu R, Hilmy N, Erizal ETB, Abbas B (1993) Radiation and chemical pretreatment of cellulosic waste. Radiat Phys Chem 42(4-6):695-698

Chrapava S, Touraud D, Rosenau T, Potthast A, Kunz W (2003) The investigation of the influence of water and temperature on the LiCl/DMAc/cellulose system. Phys Chem Chem Phys 5:1842-1847

Chung BY, Lee JT, Lee SS, Kim UJ, Wi SG, Bai HW, Cho JY (2012) A comparison of the efficiency of electron beam irradiation on enzymatic hydrolysis between 4 doses of 25 $\mathrm{kGy}$ and a single dose of $100 \mathrm{kGy}$ for bioethanol production. J Korean Soc Appl Biol Chem 55(3):385-389

Driscoll M, Stipanovic A, Winter W, Cheng K, Manning M, Spiese J, Galloway RA, Cleland MR (2009) Electron beam irradiation of cellulose. Radiat Phys Chem 78(7-8):539-542

Duquesnoy E, Castola V, Casanova J (2008) Identification and quantitative determination of carbohydrates in ethanolic extracts of two conifers using 13C NMR spectroscopy. Carbohydr Res 343(5):893-902

Emsley AM, Stevens GC (1994) Kinetics and mechanisms of the low-temperature degradation of cellulose. Cellulose 1(1):26-56

Eo MY, Fan H, Cho YJ, Kim SM, Lee SK (2016) Cellulose membrane as a biomaterial: from hydrolysis to depolymerization with electron beam. Biomat Res 20(1):16

Galant AL, Kaufman RC, Wilson JD (2015) Glucose: detection and analysis. Food Chem 188:149-160

Girisuta B, Janssen LPBM, Heeres HJ (2007) Kinetic study on the acid-catalyzed hydrolysis of cellulose to levulinic acid. Ind Eng Chem Res 46(6):1696-1708

Henniges U, Kostic M, Borgards A, Rosenau T, Potthast A (2011) Dissolution behaviour of different celluloses. Biomacromolecules 12(4):871-879

Henniges U, Okubayashi S, Rosenau T, Potthast A (2012) Irradiation of cellulosic pulps: understanding its impact on cellulose oxidation. Biomacromol 13(12):4171-4178

Henniges U, Hasani M, Potthast A, Westman G, Rosenau T (2013) Electron beam irradiation of cellulosic materials opportunities and limitations. Materials 6(5):1584-1598

Huang Y, Indrarti L, Azuma J, Okamura K (1992) Simultaneous determination of xylose and uronic-acid in beech xylan by methanolysis. Mokuzai Gakkaishi 38(12):1168-1171

Hwang Y, Park HJ-J, Potthast A, Jeong MJ (2021) Evaluation of cellulose paper degradation irradiated by an electron beam for conservation treatment. Cellulose 28:1071-1083

Kačík F, Kačíková D, Vacek V (2008) Kinetics of cellulose degradation at accelerated paper ageing. Acta Facult Xylolog 50(1):83-90 
Kato KL, Cameron RE (1999) A review of the relationship between thermally-accelerated ageing of paper and hornification. Cellulose 6(1):23-40

Kim DY, Lee BM, Koo DH, Kang PH, Jeun JP (2016) Preparation of nanocellulose from a kenaf core using E-beam irradiation and acid hydrolysis. Cellulose 23(5):3039-3049

Kontturi E, Meriluoto A, Penttilae PA, Baccile N, Malho JM, Potthast A, Rosenau T, Ruokolainen J, Serimaa R, Laine J, Sixta H (2016) Degradation and crystallization of cellulose in hydrogen chloride vapor for high-yield isolation of cellulose nanocrystals. Angew Chem Ed Engl 55(46):14455-14458

Korntner P, Hosoya T, Dietz T, Eibinger K, Reiter H, Spitzbart M, Röder T, Borgards A, Kreiner W, Mahler AK, Winter H, French AD, Henniges U, Potthast A, Rosenau T (2015) Chromophores in lignin-free cellulosic materials belong to three compound classes. Chromophores Cellul XII Cellul 22(2):1053-1062

Kumar A, Tumu VR (2019) Physicochemical properties of the electron beam irradiated bamboo powder and its biocomposites with PLA. Compos B Eng 175:107098

Laine C, Tamminen T, Vikkula A, Vuorinen T (2002) Methylation analysis as a tool for structural analysis of wood polysaccharides. Holzforschung 56(6):607-614

Larsson PT, Wickholm K, Iversen T (1997) A CP/MAS ${ }^{13} \mathrm{C}$ NMR investigation of molecular ordering in celluloses. Carbohydr Res 302(1-2):19-25

Leskinen T, Kelley SS, Argyropoulos DS (2017) E-beam irradiation \& steam explosion as biomass pretreatment, and the complex role of lignin in substrate recalcitrance. Biomass Bioenergy 103:21-28

Marques G, Gutiérrez A, del Río JC, Evtuguin DV (2010) Acetylated heteroxylan from Agave sisalana and its behavior in alkaline pulping and TCF/ECF bleaching. Carbohydr Polym 81(3):517-523

Maunu S, Liitiä T, Kauliomäki S, Hortling B, Sundquist J (2000)

${ }^{13} \mathrm{C}$ CPMAS NMR investigations of cellulose polymorphs in different pulps. Cellulose 7(2):147-159

Menart E, De Bruin G, Strlič M (2011) Dose-response functions for historic paper. Polym Degrad Stab 96(12):2029-2039

Morales-delaRosa S, Campos-Martin J, Fierro JG (2014) Optimization of the process of chemical hydrolysis of cellulose to glucose. Cellulose 21(4):2397-2407

Nocanda X, Larsson PT, Spark A, Bush T, Olsson A, Madikane M, Bissessur A, Iversen T (2007) Cross polarisation/magic angle spinning ${ }^{13} \mathrm{C}$-NMR spectroscopic studies of cellulose structural changes in hardwood dissolving pulp process. Holzforschung 61:675

Panagiotopoulos C, Sempere R (2005) Analytical methods for the determination of sugars in marine samples: a historical perspective and future directions. Limnol Oceanogr Meth 3:419-454

Postek MT, Poster DL, Vládar AE, Driscoll MS, LaVerne JA, Tsinas Z, Al-Sheikhly MI (2018) Ionizing radiation processing and its potential in advancing biorefining and nanocellulose composite materials manufacturing. Radiat Phys Chem 143:47-52

Potthast A, Rosenau T, Kosma P, Saariaho AM, Vuorinen T, Sixta $H$ (2005) On the nature of carbonyl groups in cellulosic pulps. Cellulose 12(1):43-50
Potthast A, Rosenau T, Henniges U, Schiehser S, Kosma P, Saake B, Lebioda S, Radosta S, Vorwerg W, Wetzel H, Koschella A, Heinze T, Strobin G, Sixta H, Strlic M, Isogai A (2015) Comparison testing of methods for gel permeation chromatography of cellulose: coming closer to a standard protocol. Cellulose 22(3):1591-1613

Rosenau T, Potthast A, Milacher W, Hofinger A, Kosma P (2004) Isolation and identification of residual chromophores in cellulosic materials. Polymer 45(19):6437-6443

Rumpel C, Dignac MF (2006) Chromatographic analysis of monosaccharides in a forest soil profile: analysis by gas chromatography after trifluoroacetic acid hydrolysis and reduction-acetylation. Soil Biol Biochem 38(6):1478-1481

Saeman JF, Millett MA, Lawton EJ (1952) Effect of high-energy cathode rays on cellulose. Ind Eng Chem 44(12):2848-2852

Sandy M, Manning A, Bollet F (2010) Changes in the Crystallinity of Cellulose in Response to Changes in Relative Humidity and Acid Treatment. Restaurator 31:1

Sarosi OP, Bischof RH, Potthast A (2020) Tailoring pulp cellulose with electron beam irradiation: effects of lignin and hemicellulose. ACS Sustain Chem Eng 8(18):7235-7243

Selli E, Beltrame PL, Testa G, Bonfatti AM, Rossi E, Seves A (1998) Kinetic studies on the accelerated aging of cellulosic materials. Angew Makromol Chem 257:63-69

Singh A, Das K, Sharma DK (1984) Production of reducing sugars from bagasse and rice husk by acid hydrolysis. Agric Wastes 9(2):131-145

Sundar S, Begey NS, Salamanca-Cardona L, Stipanovic A, Driscoll M (2014) Electron beam pretreatment of switchgrass to enhance enzymatic hydrolysis to produce sugars for biofuels. Carbohydr Polym 100:195-201

Sundberg A, Sundberg K, Lillandt C, Holmbom B (1996) Determination of hemicelluloses and pectins in wood and pulp fibres by acid methanolysis and gas chromatography. Nordic Pulp Pap Res J 11(4):216-226

Sundberg A, Pranovich AV, Holmbom B (2003) Chemical characterization of various types of mechanical pulp fines. Anglais 29(5):6

Wijaya YP, Putra RDD, Widyaya VT, Ha JM, Suh DJ, Kim CS (2014) Comparative study on two-step concentrated acid hydrolysis for the extraction of sugars from lignocellulosic biomass. Biores Technol 164:221-231

Willför S, Sundberg A, Hemming J, Holmbom B (2005a) Polysaccharides in some industrially important softwood species. Wood Sci Technol 39(4):245-257

Willför S, Sundberg A, Pranovich A, Holmbom B (2005b) Polysaccharides in some industrially important hardwood species. Wood Sci Technol 39(8):601-617

Willför S, Pranovich A, Tamminen T, Puls J, Laine C, Suurnäkki A, Saake B, Uotila K, Simolin H, Hemming J, Holmbom B (2009) Carbohydrate analysis of plant materials with uronic acid-containing polysaccharides-A comparison between different hydrolysis and subsequent chromatographic analytical techniques. Ind Crops Prod 29(2-3):571-580

Yoneda Y, Hettegger H, Rosenau T, Kawada T (2016) Additive tendency of substituent effects onto rate constant of acidic 
hydrolysis of methyl 4-O-methyl-beta-D-glucopyranoside. Chem Select 1(18):5715-5720

Zervos S (2010) Natural and accelerated ageing of cellulose and paper: a literature review. In: Lejeune A (ed) Cellulose: structure and properties, derivatives and industrial uses, chapter 5. Nova Publishing, Thibaut Deprez, pp 155-203

Zhang YHP, Ding SY, Mielenz JR, Cui JB, Elander RT, Laser M, Himmel ME, McMillan JR, Lynd LR (2007) Fractionating recalcitrant lignocellulose at modest reaction conditions. Biotechnol Bioeng 97(2):214-223
Zou X, Uesaka T, Gurnagul N (1996) Prediction of paper permanence by accelerated aging I. Kinetic analysis of the aging process. Cellulose 3(1):243-267

Zuckerstätter G, Schild G, Wollboldt P, Röder T, Weber HK, Sixta H (2009) The elucidation of cellulose supramolecular structure by $13 \mathrm{C}$ CP-MAS NMR. Lenzinger Ber 87:38-46

Publisher's Note Springer Nature remains neutral with regard to jurisdictional claims in published maps and institutional affiliations. 